\title{
A survey of post-amputation pains in serving military personnel
}

\author{
Dominic Aldington, ${ }^{1}$ C Small, ${ }^{2}$ D Edwards, ${ }^{2}$ J Ralph, ${ }^{2}$ P Woods, ${ }^{2}$ S Jagdish, ${ }^{3}$ \\ R A Moore ${ }^{4}$
}

'Pain Clinic, Hampshire Hospitals Foundation Trust, Winchester, Hants, UK

${ }^{2}$ Department of Anaesthesia, Queen Elizabeth University Hospital, Birmingham, UK ${ }^{3}$ Department of Anaesthesia, Queen Alexandra's Hospital, Portsmouth, Hants, UK ${ }^{4}$ Pain Relief Unit, Churchil Hospital, Oxford, UK

Correspondence to Lt Col D Aldington, RAMC, Pain Clinic, Royal Hampshire County Hospital, Winchester, Hants SO22 5SG, UK d.aldington@nhs.net

Received 13 March 2013 Revised 2 May 2013 Accepted 16 June 2013 Published Online First 13 July 2013

\begin{abstract}
Introduction Amputation is a common injury in survivors of current military conflicts. The primary aim of this study was to establish the prevalence rate of phantom limb pain (PLP) in military personnel undergoing rehabilitation at the UK's Defence Medical Rehabilitation Centre. The secondary aims were to establish treatment failure rates and prevalence rates of phantom limb sensations (PLS) and residual limb pains (RLP).
\end{abstract}

Method A questionnaire survey was developed from that used in a previous study of pains in veterans. Questions were asked of the intensity of PLP, RLP and PLS over the previous month and the entire time since amputation. Treatment failure was defined as greater than 'mild' pain. A literature review for similar studies was undertaken.

Results There were 48 responders with 65 amputations. PLP in the previous month was reported by $49 \%$ of respondents and $20 \%$ were classed as treatment failures; $76 \%$ had PLP at some point and $56 \%$ were analgesic failures. PLS was commoner with $70 \%$ reported over the previous month and $66 \%$ at any time. $65 \%$ had RLP over the previous month, $31 \%$ were treatment failures and $80 \%$ had experienced RLP at some point and $63 \%$ of these were failures of treatment. Eight other papers were found for comparison.

Conclusions This is the first paper that describes prevalence of pains associated with amputation in a serving military population. It also describes the use of analgesic failure as a concept and provides an encouraging rate of as low as $20 \%$ in this population.

\section{INTRODUCTION}

Military conflict is associated with limb loss and its sequellae. Indeed, the phrase 'phantom limb' was introduced to the medical lexicon by Weir Mitchell in 1872 following his observations of amputees during the American Civil War ${ }^{1}$ although Ambrose Paré had already described some of the symptoms 300 years earlier during the Piédmont campaign (1537-1538). ${ }^{2}$

The primary aim of this survey was to establish the prevalence of phantom limb pain (PLP) among casualties at the UK's Defence Medical Rehabilitation Centre (DMRC) at Headley Court. The secondary aims were to calculate PLP management failure rates, the prevalence of residual limb ('stump') pain (RLP) and phantom limb sensations (PLS) and to compare these results with previous studies.

\section{METHOD}

Amputees were defined as individuals with part of a limb missing; single digit amputation was excluded.

\section{Key messages}

In all, $49 \%$ of amputations gave rise to phantom limb pain in the month before being questioned; $20 \%$ of these were classed as analgesic management failures which compares favourably with other studies.

- Residual limb pain is more common and more likely to be an analgesic failure.

- Phantom limb symptoms are common occurring in $70 \%$ of amputations.

- The use of analgesic failure as an output measure should be encouraged.

Casualties with limb amputations undergoing rehabilitation at DMRC over a 9-month period were approached for inclusion in the survey as they were identified over the course of their rehabilitation; there were no exclusion criteria. Those who consented to participate were provided with an anonymous questionnaire based on that used in a previous study on veterans. ${ }^{3}$ Questions were asked about PLP, PLS and RLP and were aimed at establishing the maximum intensity of the pain or sensation during two time periods, the previous month or the entire history of being an amputee. This was measured using a four point categorical scale: None, Mild, Moderate and Severe. PLP was defined as pain in the missing limb, PLS as a nonpainful sensation in the missing limb and RLP as pain in the 'stump'. The unit of analysis was amputations and not individual patients.

As previously described, pain management 'failure' was defined as a pain intensity of greater than mild, more than 1 on a $0-3$ numerical scale or more than 3 on a $0-10$ numerical scale $;{ }^{4}$ space was provided for free text comments to be made and these were analysed for common themes.

A search of PubMed and Google Scholar for articles reporting on phantom pain using a series of free text words alone and in combination ('phantom limb', 'residual limb', 'stump', 'amputation', 'pain') was undertaken. Any study design was considered for inclusion and retrieved articles were read for other sources of data.

\section{RESULTS}

There were 48 individual responders although not all responses were complete and all respondents were still serving in the military. The 
mean age was 28.8 years, with an SD of 6.7 years and a range of $18-46$ years.

There were 11 double amputees (five upper limb/lower limb and six bilateral lower limb), and three triple amputees (bilateral lower limb and one upper limb), the remainder were single amputees. Results were analysed with this denominator of 65 amputations (six left upper limb, five right upper limb, 28 left lower limb and 26 right lower limb amputations).

A total of 15 responses were within 13 weeks of injury, six responses were from 13 to 26 weeks, 11 from 26 to 52 weeks and 16 over 1 year with the maximum being 15 years following the incident.

\section{Phantom limb pain}

In all, 32 (49\%) responses indicated PLP at some point over the previous 1 month; 20\% (13) of all responses were classed as analgesic failures. A total of 76\% (49) of responses indicated PLP at some point since injury; 36 (56\%) of these were classed as analgesic failures (Figure 1).

Free text analysis showed the pain described as itching by two, crushing by two and by one as either electric shock, burning, swelling, stabbing or cramping. When describing things that help to reduce the pain, 14 stated moving or rubbing the stump helped, seven used medication, four reading or listening to music or staying busy, two moving the other (remaining) limb, and one wearing the prosthetic. Only one individual commented that his pain was made worse when defecating. Twelve stated nothing helped their pain.

\section{Phantom limb sensation}

PLS, rather than pain, over the previous month occurred in $70 \%$ (45) and over the historical period was reported in $66 \%$ (43) of amputations; the level of 'problem' associated with the sensation was reported as a moderate or severe intensity in $41 \%$ (26) over the last month and 42\% (27) historically.

Free text analysis showed 28 individuals reported their phantom limb was in a normal position, 16 that it had telescoped (moved proximally), three that it was twisted and one that it was cramped; two reported a degree of itching in their limb. Two individuals commented that their PLS was helped by massaging the stump, two by wearing their prosthetic, two with movement, one with distraction and one with rubbing the pillow distal to the stump when lying in bed.

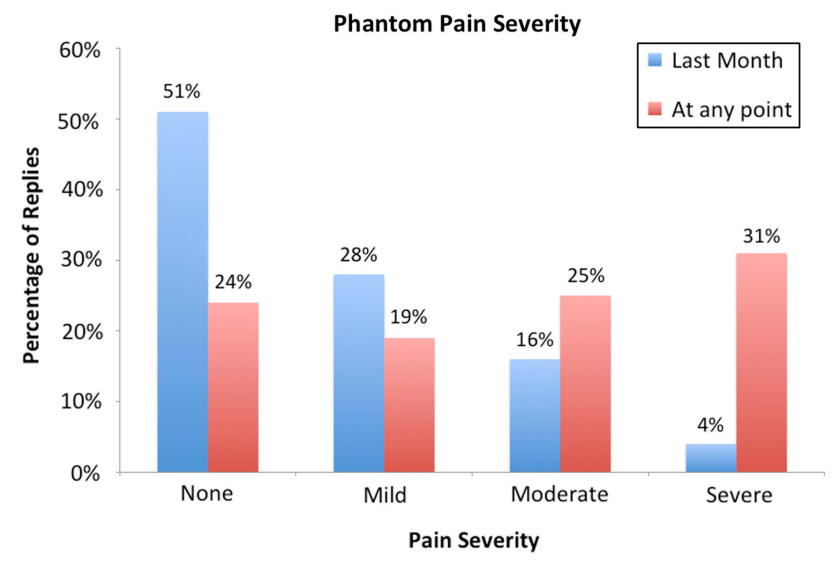

Figure 1 The percentage of replies against severity of phantom limb pain in 65 amputations for the previous month and at any point since amputation.
Residual limb pains

Overall, 65\% (42) of responses had RLP pain at some point over the previous month; 31\% (20) were classed as analgesic failures. A total of $80 \%$ of responses experienced RLP at some point historically; 63\% (41) were classed as analgesic failures (Figure 2).

Free text analysis revealed that massage and movement of the stump helped (16 times), seven respondents said removal of the prosthetic helped, while one individual felt better with the prosthetic on. Rest was mentioned seven times as helping, while medication was reported nine times and ice twice. Four times it was suggested things were better at night while six times they were worse. One individual made the comment that his pain was worse when defecating; five times the comment was made that the pain was entirely random and nothing helped it.

\section{DISCUSSION}

The literature reporting PLP data is relatively spartan, summarised in Table 1 and provides a baseline against which to compare our data. The prevalence of PLP ranged from $61 \%$ to $100 \%$ and phantom pain management failure rates varied between $22 \%$ and $92 \%$, depending on duration and exact definition of failure. A comparison of the results is shown in Figure 3.

A PLP prevalence over the previous month of $49 \%$ appears to be relatively low, but more important is the 20\% PLP failure rate, which is also low. Comparing results for 'historical' and for 'the last month', it appears that the prevalence of PLP reduces with time. This reduction in pain with time is important for casualties to know early in their management so that they realise their pain is unlikely to be constant.

In all, $80 \%$ of amputees experience RLP which given the nature of amputations secondary to trauma is not entirely surprising. However, this remains a result of note as it is often assumed by wider society that the only pain amputees have is PLP. RLP also appears to reduce with time. The RLP management failure rate of $31 \%$ over the previous month is also encouraging especially as approximately a quarter are still within 13 weeks of amputation.

Conversely, problems with PLS do not seem to change so much over time. Whether a sensation that is a severe problem is really a pain suggests there was some confusion despite the questionnaire specifically asking about issues other than pain,

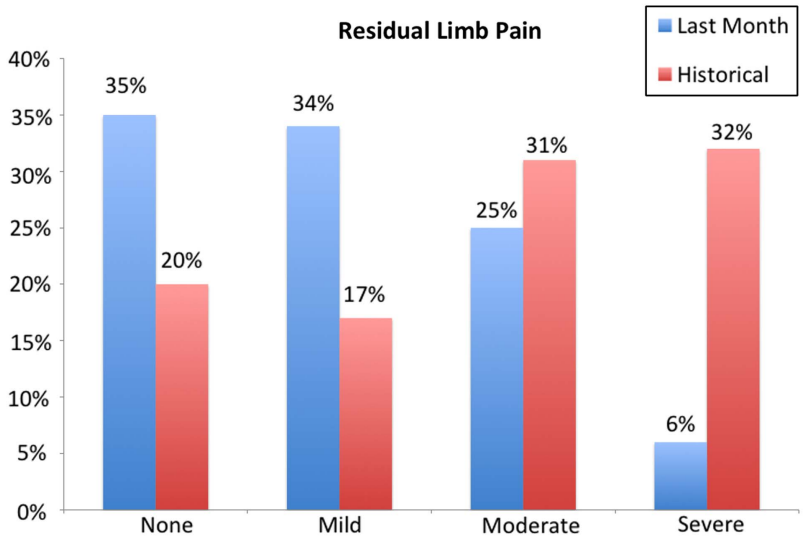

Figure 2 The percentage of replies against severity of residual limb pain in 65 amputations for either the previous month or at any point since amputation. 
Table 1 A review of studies reporting data for phantom limb pain (PLP) and residual limb pain (RLP) in which treatment failure rates could be established

\begin{tabular}{|c|c|c|c|c|c|c|c|c|}
\hline \multirow{2}{*}{$\begin{array}{l}\text { Study } \\
\text { number } \\
\text { (See Figure 3) }\end{array}$} & \multirow[b]{2}{*}{ Author (year) } & \multirow[b]{2}{*}{ Population } & \multirow[b]{2}{*}{$\mathbf{N}$} & \multicolumn{2}{|c|}{ Prevalence (\%) } & \multicolumn{2}{|c|}{ Failure rate $(\%)$} & \multirow[b]{2}{*}{ Comments } \\
\hline & & & & PLP & RLP & PLP & RLP & \\
\hline 1 & Parkes $(1973)^{5}$ & Not specified & 46 & 61 & - & 30 & - & $\begin{array}{l}\text { Severity measured as mild, moderate and severe. } \\
\text { Score taken at } 13 \text { months after amputation }\end{array}$ \\
\hline 2 & $\begin{array}{l}\text { Hoaglund et al } \\
(1983)^{6}\end{array}$ & Veterans & 197 & 68 & - & - & 54 & $\begin{array}{l}\text { Severity measured as mild, moderate and severe. } \\
\text { Time period unclear. Unable to calculate RLP } \\
\text { prevalence or PLP failure rate }\end{array}$ \\
\hline 3 & $\begin{array}{l}\text { Sherman et al } \\
(1984)^{7}\end{array}$ & Veterans & 2694 & 78 & - & 69 & - & $\begin{array}{l}0-10 \text { numerical rating scale used, but split into } \\
\text { worse, average and least pain. 'Average' result used } \\
\text { here. Time span for questionnaire unclear as both } \\
\text { 'ever and 'now' are used }\end{array}$ \\
\hline 4 & $\begin{array}{l}\text { Ehde et al } \\
(2000)^{8}\end{array}$ & $\begin{array}{l}\text { Veterans and civilian } \\
\text { lower limb amputees at } \\
\text { least } 6 \text { months from } \\
\text { amputation }\end{array}$ & 255 & 72 & 74 & 48 & 60 & $\begin{array}{l}\text { Intensity over previous } 3 \text { months measured on } 11 \\
\text { point numerical rating scale. Mean pain scores } \\
\text { given. Failure rate from a 'bothersome' score greater } \\
\text { than mild }\end{array}$ \\
\hline 5 & $\begin{array}{l}\text { Gallagher et al } \\
(2001)^{9}\end{array}$ & Not specified & 104 & - & - & $\begin{array}{l}67 \text { (i) } \\
22 \text { (ii) }\end{array}$ & $\begin{array}{l}87 \text { (i) } \\
39 \text { (ii) }\end{array}$ & $\begin{array}{l}\text { Severity over previous } 1 \text { week measured as mild, } \\
\text { discomforting, distressing, horrible and excruciating. } \\
\text { Failure greater than mild (i) and discomforting (ii) }\end{array}$ \\
\hline 6 & $\begin{array}{l}\text { Whyte and Niven } \\
(2001)^{10}\end{array}$ & Not specified & 89 & 100 & - & 70 & - & $\begin{array}{l}\text { Intensity measured on } 0-10 \text { numerical rating scale } \\
\text { and over } 7 \text { days. Here failure is }>3 / 10 \text { with the } \\
\text { score averaged over the week }\end{array}$ \\
\hline 7 & $\begin{array}{l}\text { Ephraim et al } \\
(2005)^{11}\end{array}$ & Not specified & 914 & 80 & 68 & 53 & 40 & $\begin{array}{l}\text { Intensity over previous } 4 \text { weeks measured as mild, } \\
\text { moderate and severe }\end{array}$ \\
\hline 8 & $\begin{array}{l}\text { Desmond and } \\
\text { MacLachlan } \\
(2010)^{12}\end{array}$ & $\begin{array}{l}\text { Veterans with upper } \\
\text { limb amputations; mean } \\
\text { time since amputation } \\
50.1 \text { years }\end{array}$ & $\begin{array}{l}P L P=60 \\
R L P=61\end{array}$ & 64 & 55 & $\begin{array}{l}88 \text { (i) } \\
37 \text { (ii) }\end{array}$ & $\begin{array}{l}89 \text { (i) } \\
44 \text { (ii) }\end{array}$ & $\begin{array}{l}\text { Intensity over previous } 1 \text { week measured on a } \\
5 \text {-point scale: mild, discomforting, distressing, } \\
\text { horrible and excruciating. Failure rates taken as } \\
\text { greater than mild (i) or greater than discomforting } \\
\text { (ii) }\end{array}$ \\
\hline 9 & Our study & Serving personnel & 65 & 49 & 65 & 20 & 31 & Previous 4 weeks \\
\hline & & & 65 & 76 & 80 & 56 & 63 & At any point since injury \\
\hline
\end{tabular}

echoed by the fact that respondents reported a $70 \%$ rate of PLS in the previous month but only $66 \%$ historically.

The free text comments serve to highlight the wide variety of things that can help these patients, the importance of the individual being encouraged to find out what works for them and to be aware that this may change with time. This is important as there is no agreed single optimum treatment for pains associated with amputation. ${ }^{13} 14$

Figure 3 A bubble plot of failure rates described in studies of phantom limb pain numbered according to Table 1. The figures to the right of the bubbles refer to the number of units of analysis in that study. There was no result for Study 5 that could be calculated. Studies 1 and 7 gave two results depending upon the definition of failure (see Table 1 for more information). Study 9 is this study and provides results for 'last month' and 'at any point'.
It was gratifying to see that some volunteered the information that their medication helped them to manage their pain; with numbers needed to treat commonly in the order of $4-5$, we know anti-neuropathic agents do not help everybody. ${ }^{15}$ It was also interesting to note that an increase in pain with defecation was only reported twice as anecdotally it is a more common presentation. 
Traditional reports of PLP and RLP rely on prevalence rates as a dichotomous output. Although not without its value, these show significant variation even here, ranging from $49 \%$ in our study to $100 \%,{ }^{10}$ which may call into question their clinical value. Another common study output is to provide mean pain scores, which is potentially problematic as pain scales are nonparametric and such a report gives little indication of treatment success or failure.

This is the first paper that has sought to establish rates of treatment failure in the management of PLP and RLP in a serving military population undergoing rehabilitation. In defining treatment failure it must be stressed that it does not indicate substandard treatment but only that the treatment does not achieve the typical goals of the population. There are many important questions outside the power of this survey that remain unanswered, which may form the foundations for future enquiry; these include not distinguishing between primary amputation at the initial incident and secondary or semi-elective amputation, the contribution of specific interventions such as ketamine use, continuous peripheral nerve block catheters and early pregabalin or amitriptyline all of which are encouraged in these casualties. ${ }^{16}$ Similarly, we have not sought to untangle issues around recall of pain, nor explicitly of the effect between time passed and pain levels. The contributions of mental health disorders, mild traumatic brain injury or heterotrophic ossification have not been examined nor the effects of specific rehabilitation interventions. Finally this study focused not on individual responses but on 'limb responses'.

\section{CONCLUSIONS}

Over the month before they were questioned almost half of amputations had PLP and 20\% were analgesic failures, two-thirds had RLP and 31\% were analgesic failures and 70\% experienced PLS. It appears that with time the pains become less significant. We suggest that future papers describe not just underlying prevalence rates but more importantly treatment failure rates.

Persistent pains of any kind are never easy to understand. These military personnel, at the point of being questioned, were all employed and undergoing rehabilitation surrounded by likeminded colleagues within a military environment. What will happen when they leave this environment and become civilians will be of significance to them, to their subsequent healthcare providers and to the wider society.
Acknowledgements The authors would like to thank the staff of DMRC and the Oxford Pain Research Unit for their assistance and support with this project and the staff of DMRC Headley Court for their assistance with this survey.

Contributors All authors contributed to the design of the study. DA, CS, DE, JR, PW and SJ collected data. RAM helped with the write up and the literature review. $D A$ is the guarantor of the work.

\section{Competing interests None.}

Ethics approval Ethical approval for this cross-sectional questionnaire survey was granted by the Ministry of Defence Research Ethics Committee (study no: 0832/187).

Provenance and peer review Not commissioned; externally peer reviewed.

\section{REFERENCES}

1 Mitchell SW. Injuries of nerves and their consequences. Philadelphia: JB Lippincott, 1872.

2 Keil G. So-called initial description of phantom pain by Ambroise Paré. "Chose digne d'admiration et quasi incredible": the 'douleur ès parties mortes et amputées'. Fortschr Med 1990;108:62-6.

3 Wartan SW, Hamann W, Wedley JR, et al. Phantom pain and sensation among British veteran amputees. Br J Anaesthesia 1997;78:652-9.

4 Moore RA, Eccleston C, Derry $S$, et al. "Evidence" in chronic pain-establishing best practice in the reporting of systematic reviews. Pain 2010;150:386-9.

5 Parkes CM. Factors determining the persistence of phantom pain in the amputee. J Psychosom Res 1973;17:97-108.

6 Hoaglund $F$, Jergesen $\mathrm{H}$, Wilson $\mathrm{L}$, et al. Evaluation of problems and needs of veteran lower-limb amputees in the San Francisco Bay Area during the period 1977-1980. J Rehabil R D 1983:20:57.

7 Sherman RA, Sherman CJ, Parker L. Chronic phantom and stump pain among American veterans: results of a survey. Pain 1984;18:83-95.

8 Ehde DM, Czerniecki JM, Smith DG, et al. Chronic phantom sensations, phantom pain, residual limb pain, and other regional pain after lower limb amputation. Arch Phys Med Rehabil 2000;81:1039-44.

9 Gallagher P, Allen D, Maclachlan M. Phantom limb pain and residual limb pain following lower limb amputation: a descriptive analysis. Disabil Rehabil 2001;23:522-30

10 Whyte AS, Niven CA. Variation in phantom limb pain: results of a diary study. J Pain Symptom Manage 2001;22:947-53.

11 Ephraim PL, Wegener ST, MacKenzie, et al. Phantom pain, residual limb pain, and back pain in amputees: results of a national survey. Arch Phys Med Rehabil 2005:86:1910-19.

12 Desmond DM, MacLachlan M. Prevalence and characteristics of phantom limb pain and residual limb pain in the long term after upper limb amputation. Int I Rehabil Res 2010;33:279-82.

13 Sherman RA, Sherman CJ, Gall NG. A survey of current phantom limb pain treatment in the United States. Pain 1980;8:85-99.

14 Sherman RA, Sherman CJ. Prevalence and characteristics of chronic phantom limb pain among American veterans. Results of a trial survey. Am J Phys Med 1983:62:227-38.

15 Finnerup NB, Otto M, Mcquay HJ, et al. Algorithm for neuropathic pain treatment: an evidence based proposal. Pain 2005;118:289-305.

16 Aldington DJ, Mcquay HJ, Moore RA. End-to-end military pain management. Philos Trans R Soc Lond, B, Biol Sci 2011;366:268-75. 